\section{Engineering geology}

\section{J. L. Knill}

Principles of Engineering Geology. By P. B. Attewell and I. W. Farmer. Pp. $\mathrm{xxx}+1045$. (Chapman and Hall: London; Halsted/Wiley: New York, 1976.) £25.

ENGINEERING GEOLOGY has been the main growth subject within the industriallyorientated aspects of the Earth sciences during the past two decades. The question remains, however, as to whether the success of engineering geology has been a consequence of the development of a new discipline, or is more fairly a reflection of the vocational opportunities for geologists within the construction industry.

The origins of engineering geology, as it is now defined, lay in the heavy construction industry in the early years of this century when geologists were invited to advise firstly on ground problems encountered during construction, and subsequently to assist in the prediction of difficulties during the earlier phases of investigation and design. At that time soil and rock mechanics did not exist as such and so it was natural in civil engineering for geologists to continue to be employed in the United States for the following decades; it was not until the 1950 s that systematic education and growth in employment opportunities began to develop on a world-wide scale.

Soil mechanics was, by then, a wellestablished branch of engineering science, and subjects such as rock mechanics and hydrogeology were also firmly established. Perhaps it was inevitable that engineering geology has tended to move into a central position within the engineering earth sciences, attempting to link together the interactions between rock, soil and water as engineering materials within the realities of natural geological conditions and engineering problem-solving during investigation, design and construction.

There is, in consequence, a considerable element of choice not only in the balance between the component subject areas but also in the extent to which these subject areas are integrated with one another. On the one hand, it can be argued that the professional engineering geologist is essentially a geologist and his knowledge of the engineering disciplines should be maintained at a level that enables him to be able to communicate effectively in an engineering environment. On the other hand, engineering geology can be viewed as representing a balanced approach towards geotechnical engineering drawing together soil and rock mechanics, hydrogeology and geology into a unified whole to that the engineering geologist adopts the role of an engineer.

The authors of this textbook have been concerned for some years with the organisation of a postgraduate course in engineering geology at Durham University, and the structure of the book reflects both the philosophy of this course, and the associated research activities. The book falls into two broad sections, the earlier part providing an approach towards the study of the engineering properties of engineering soils and rocks, whereas the later part deals with more practical, engineering-orientated topics.

The opening chapter provides a general coverage of minerals and rocks, drawing particular attention to clay minerals and their identification and this is followed by a concise review of soil mechanics. The succeeding chapter is a major treatment of the geotechnical and geological characteristics of clays and clay shales, much of the relevant material having been drawn from unpublished research. The text turns to rock as a material, and the influence of symmetry and preferred orientation of micro- and macrofabrics on the properties of rocks and soils. The progressive approach of the authors towards the development of macroscopic fabric diagrams related to stability/instability fields is of particular interest.

At this point the book seems to change step, turning systematically to site investigation, groundwater, soil and rock slope stability, techniques of ground improve-

\section{Dating in archaeology}

\section{Elizabeth Slater}

Dating in Archaeology: A Guide to Scientific Techniques. By S. Fleming. Pp. 272. (Dent: London, 1976.) $£ 8.95$.

A IJECADF AGO, when the application of scientific dating techniques to archaeological material was gaining momentum, this book would have been a welcome addition to the bookshelves of archaeologists. Non-specialists then needed a general introduction to the available methods, with some indication of their potential and limitation, to illustrate the wealth of information that could be extracted from archaeological material and to assist them in the assessment of the validity of the dates produced.

This book follows a standard format with sections devoted to the main dating methods, giving information on the method, the materials to which it can be applied, its accuracy, associated ment, and the assessment and control of water resources. Most surprisingly, the application of geology to underground works and foundations, two important facets of the subject, are almost completely ignored.

This textbook is an interesting view of engineering geology, more strongly reflecting the engineering aspects than the geological. The arrangement of the book into two parts with somewhat different themes, is, however, not wholly satisfying nor has there been adequate control of excessive detail which penetrates into the text. For a book in excess of a thousand pages and at a price that will deter many, more careful structuring of the book with regard to the potential market could have yielded a shorter, cheaper and more comprehensive text.

The publishers suggest that the book will be of value for courses in both civil engineering and geology; at this price it can only possibly attract those who have already chosen engineering geology or geotechnical engineering as their career field. It has also been suggested by the publishers that "the book will itself eventually become synonomous with the subject area of engineering geology". Many will debate this prediction but it does not detract from the valuable service that the authors have done in drawing together so much useful material.

J. L. Knill is Professor of Engineering Geology at Imperial College, University of London, $U K$

problems and selected examples of its application. There are eight main chapters, plus a useful introductory chapter on the chronological patterns that were developed before the main impact of scientific dating methods, and a final chapter on scientific techniques applied to art history. The methods which reveal aspects of climatic changes are considered in an appendix and the other appendix contains an outline of the pre-dose thermoluminescence technique.

One of the greatest problems facing archaeologists is the interpretation of the information yielded by scientific dating methods. 'They are left with dates, plus associated errors, and a bewildering array of methods for the manipulation of the data. This problem is more readily acknowledged in the case of radiocarbon dating but it is inherent in all dating methods. The author gives no guidance in this matter, nor does he mention all possible procedures. He may feel that it would be premature to do so, and, as he says, "So many of the finer details of radiocarbon variations remain unresolved that no strong attempt has yet been made to routinely correct older conventional dates...". But he adds: "the 